\title{
Bulk density and porosity distributions in a compost pile
}

\author{
J.T. VAN GINKEL ${ }^{1}$, P.A.C. RAATS ${ }^{1,2, *}$ AND I.A. VAN HANEGHEM ${ }^{3}$ \\ ${ }^{1}$ Research Institute for Agrobiology and Soil Fertility Research (AB-DLO), P.O.Box 14, \\ NL-6700 AA Wageningen, The Netherlands \\ 2 Wageningen Agricultural University, Department of Agricultural, Environmental and \\ Systems Technology, Dreijenlaan 4, NL-6703 HA Wageningen, The Netherlands \\ 3 Wageningen Agricultural University, Department of Agricultural, Environmental and \\ Systems Technology, Bomenweg 4, 6703 HD Wageningen, The Netherlands \\ * Corresponding author
}

Received 18 May 1998; accepted 17 June 1999

\begin{abstract}
This paper mainly deals with the description of the initial distribution of bulk density and porosity at the moment a compost pile is built or rebuilt. A relationship between bulk density and vertical position in a pile is deduced from theoretical and empirical considerations. Formulae to calculate the air filled volume fraction and the true densities of the solid phase and of the organic matter are also derived. The true density of dry matter is used in the computation of porosity distributions. The relationships between bulk density and height and between air-filled volume fraction and height are shown to be valid for composting material consisting of chopped wheat straw and chicken manure. The check of this validity is limited to total bulk density values ranging from 150 to $950 \mathrm{~kg} \mathrm{~m}^{-3}$, with values of dry matter content varying between 18 and $28 \%$ (w.b.). Moreover, the gravimetric dry matter content must be constant throughout the total cross section of the pile. The error in the calculated bulk densities and air-filled volume fractions was found to be $12 \%$ at a reliability level of $95 \%$. It seems likely that the presented equations will give reasonable results for other values of dry matter content and other kinds of chopped fibrous materials as long as the gravimetric dry matter content remains independent of height.
\end{abstract}

Keywords: compost, settlement, decomposition, transport processes

\section{Introduction}

Transport of mass and heat in a compost pile is significantly affected by the geometry and size distribution of the pores and the composition of the composting material. Therefore it is at least necessary to have information about the spatial distribution of porosity. Porosity can be calculated from dry matter content, true density of dry matter and total bulk density. Dry matter content and true density of dry matter are easily measured in the laboratory. To describe the bulk density distribution, distinction is made between time dependent and time independent processes. 
The time independent process results from the compressibility of composting material (Randle and Flegg, 1985). Compressibility is defined as the reciprocal of the resistance of the material against mechanical deformation, or more precisely, as the ratio between deformation and stress. Due to this property the bulk density is a function of the local pressure and therefore depends on the position in the pile.

The time dependent process is illustrated by the results of Lopez-Real (1990), who examined the material losses of a seaweed/straw mixture after 28 days of composting in a forced aeration system with turning. He found a total weight reduction of $50 \%$, a volume reduction of $77 \%$, and a bulk density increase from 310 to $670 \mathrm{~kg} \mathrm{~m}^{-3}$, indicating that settlement occurred. Settlement is defined as the increase of mechanical deformation as a function of time under constant pressure conditions. When a compost pile is built, the initial bulk density distribution is only determined by the compressibility of the composting material. However, during the process bulk density and porosity are also influenced by the combined effects of subsidence, loss of organic matter due to biological degradation processes and change of water content due to transport processes.

In this paper we mainly describe the initial distribution of bulk density and porosity at the moment the pile is built or rebuilt. For composting material, no detailed discussion of the relation between bulk density and position was found in the literature. In section 2 we deduce such a relation from theoretical and empirical considerations. We also derive formulae to calculate the air filled volume fraction and the true densities of the solid phase and the organic matter. The true density of dry matter is used in the computation of porosity distributions. In section 3 the design of the experiments is described. The results are presented in section 4. A discussion of the results is given in section 5. Unless otherwise stated, the errors of experimentally determined quantities are expressed as standard error of the mean (Lyons, 1991).

This paper is based on the PhD thesis of the senior author (Van Ginkel, 1996). In the thesis a wide range of other physical, biochemical, and calorimetric aspects are dealt with.

\section{Modeling composition and compression of compost}

\section{Description of the composition of compost}

Compost can be regarded as a mixture of a solid phase $s$, a liquid phase $l$ and a gaseous phase $g$, with each of these phases themselves being mixtures of numerous constituents (cf. Raats, 1984). The volume fractions $\theta_{i}=\left(\theta_{s}, \theta_{l}, \theta_{g}\right)$ of the phases are subject to the constraint

$$
\sum \theta_{i}=\theta_{s}+\theta_{l}+\theta_{g}=1
$$

The true densities $\gamma_{i}=\left(\gamma_{s}, \gamma_{l}, \gamma_{g}\right)$ of the phases are defined as masses per unit volume of the phase $i$. We prefer to take the volume fractions, with the constraint defined by equation (1), and the true densities of the phases as the basic compositional vari- 
ables. All other compositional variables are logically deduced from these basic variables. This way we avoid giving ad hoc, unrelated definitions of terms.

The bulk densities $\rho_{i}=\left(\rho_{s}, \rho_{l}, \rho_{g}\right)$ of the phases are defined by:

$$
\rho_{i}=\theta_{i} \gamma_{i}
$$

Solving (2) for $\theta_{i}$ gives:

$$
\theta_{i}=\rho_{i} / \gamma_{i}
$$

Introducing (3) in the constraint (1) gives:

$$
\sum \rho_{i} / \gamma_{i}=\rho / \gamma_{s}+\rho_{l} / \gamma_{l}+\rho_{g} / \gamma_{g}=1
$$

The wetness $w$ is defined as:

$$
w=\rho_{l} / \rho_{s}
$$

The total bulk density $\rho$ is defined as the sum of the bulk densities of the phases:

$$
\rho=\sum \rho_{i}=\rho_{s}+\rho_{l}+\rho_{g}
$$

Introducing (2) in (6) results in:

$$
\rho=\sum \theta_{i} \gamma_{i}=\theta_{s} \gamma_{s}+\theta_{l} \gamma_{l}+\theta_{g} \gamma_{g}
$$

The dry matter content $d_{s}$ is defined as:

$$
d_{s}=\rho_{s} / \rho
$$

Next we show that the total bulk density $\rho$ and the dry matter content $d_{s}$ can be used to derive convenient expressions for the volume fraction $\theta_{g}$ of the gaseous phase and the true density $\gamma_{s}$ of the solid phase.

First we consider the volume fraction $\theta_{g}$ of the gaseous phase. Solving the constraint (1) for $\theta_{g}$ gives:

$$
\theta_{g}=1-\theta_{s}-\theta_{l}
$$

Introducing (3) in (9) results in:

$$
\theta_{g}=1-\rho_{s} / \gamma_{s}-\rho_{l} / \gamma_{l}
$$

After solving (6) for $\rho_{l}$ and substituting the result in (10), it follows that:

$$
\theta_{g}=1-\rho_{s} / \gamma_{s}-\left(\rho-\rho_{s}-\rho_{g}\right) / \gamma_{l}
$$


Making use of the fact that $\rho_{g} \ll \rho_{s}$, solving (8) for $\rho_{s}$, and substituting the resulting expression in (11) gives:

$$
\theta_{g}=1-\left[d_{s} / \gamma_{s}+\left(1-d_{s}\right) / \gamma_{l}\right] \rho
$$

or

$$
\theta_{g}=1-\left(1 / \gamma_{l}+d_{s} / \gamma_{s}-d_{s} / \gamma_{l}\right) \rho
$$

Equations (12) and (13) show that the volume fraction of the gaseous phase $\theta_{g}$ can be calculated from the total bulk density $\rho$, the dry matter content $d_{s}$, and the true densities $\gamma_{s}$ and $\gamma_{l}$.

Next we consider the true density $\gamma_{s}$ of the solid phase. Solving (4) for $\gamma_{s}$ gives:

$$
\gamma_{s}=\rho_{s} /\left(1-\rho_{l} / \gamma_{l}-\rho_{g} / \gamma_{g}\right) \text {. }
$$

Expressing, as above, the bulk density of the water $\rho_{l s}$ in terms of the total density $\rho$ and the dry matter content $d_{s}$, and further replacing $\rho_{g} / \gamma_{g}$ by $\theta_{g}$ and $\rho_{s}$ by $\rho d_{s}$ it follows that:

$$
\gamma_{s}=\left(\rho d_{s}\right) /\left[1-\left(1-d_{s}\right) \rho / \gamma_{l}-\theta_{g}\right] .
$$

Equation (15) shows that the true density of the solid phase $\gamma_{s}$ can be calculated from the total bulk density $\rho$, the dry matter content $d_{s}$, the true density of the liquid phase $\gamma_{l}$, and the volume fraction of the gaseous phase $\theta_{g}$.

Generally the solid phase of compost is itself a mixture of numerous compounds. For our purposes it is sufficient to distinguish the organic subphase $o$ and inorganic ('ash') subphase $a$, each characterized, respectively, by their individual volume fractions $\theta_{o}$ and $\theta_{a}$, true densities $\gamma_{o}$ and $\gamma_{a}$, and bulk densities $\rho_{o}$ and $\rho_{a}$, such that:

$$
\rho_{o}=\theta_{o} \gamma_{o}
$$

and

$$
\rho_{a}=\theta_{a} \gamma_{a}
$$

Summation of (16) and (17) gives equation (2) for $s$ :

$$
\rho_{s}=\theta_{s} \gamma_{s}
$$

with $\theta_{s}$ given by:

$$
\theta_{s}=\theta_{o}+\theta_{a}
$$


Equation (19) is a necessary consequence of splitting the solid phase in an organic subphase and an inorganic ('ash') subphase. From the equality of the right hand side of (18) to the sum of the right hand sides of (16) and (17), it follows that the true density of the organic subphase is given by:

$$
\gamma_{o}=\rho_{o} /\left(\rho_{s} / \gamma_{s}-\rho_{a} / \gamma_{a}\right)
$$

An alternative form of (20) can be obtained by defining the concentrations $c_{o}$ and $c_{a}$ of, respectively, the organic and inorganic ('ash') subphases:

$$
\begin{aligned}
& c_{o}=\rho_{o} / \rho_{s}, \\
& c_{a}=\rho_{a} / \rho_{s} .
\end{aligned}
$$

Clearly the sum of these two concentrations is unity:

$$
c_{o}+c_{a}=1
$$

Dividing in (20) the numerator and the denominator by $\rho_{s}$ and making use of (21), (22) and (23), it follows:

$$
\gamma_{o}=\left(1-c_{a}\right) /\left(1 / \gamma_{s}-c_{a} / \gamma_{a}\right)
$$

Equation (24) shows that the true density $\gamma_{o}$ of the organic subphase can be calculated from the true densities $\gamma_{s}$ and $\gamma_{a}$, and the concentration $c_{a}$ of the inorganic ('ash') subphase.

\section{Compression of compost}

The total equilibrium force balance in three dimensions $x_{i}=\left(x_{1}, x_{2}, x_{3}\right)$ can be written as:

$$
\frac{\partial}{\partial x_{i}} T_{i j}+\rho g_{j}=0
$$

where $T_{i j}$ is the stress tensor, whose $3 \times 3$ matrix of components describes the normal and shear stresses in the compost, and $g_{j}$ the gravitational force per unit mass. We simplify the force balance by means of three assumptions:

1. The vertical direction $z$ (positive upward) is a principal direction and the principal stress in that direction is $\sigma[\mathrm{N} \mathrm{m}]$ :

$$
\frac{\partial}{\partial z} \sigma+\rho g=0
$$

Equation (26), which may be regarded as the vertical force balance of an infinitesi- 


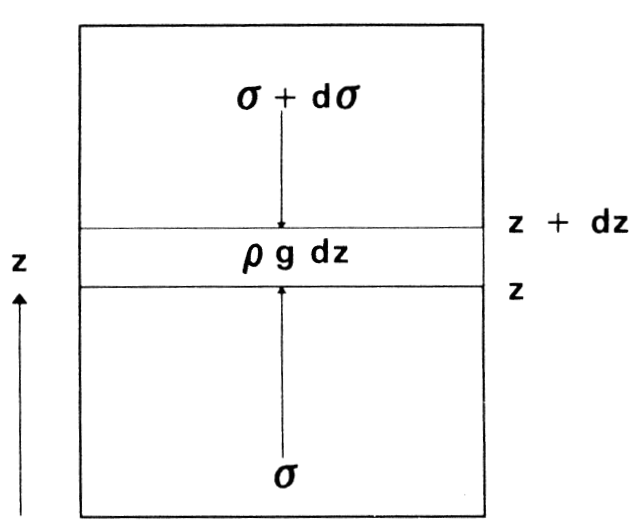

Figure 1. Force balance of a thin layer of composting material.

mally thin layer of composting material somewhere in the pile (see figure 1), is used to derive the relation between bulk density and height in a compost pile.

2. The constitutive equation for $\sigma$ is

$$
\sigma=E\left(\rho_{s}-\rho_{s u}\right)
$$

in which $E\left\{\mathrm{~J} \mathrm{~kg}^{-1}\right\}$ is a measure of the resistance of the composting material against deformation and $\rho_{s u}$ is the unloaded dry bulk density $\left\{\mathrm{kg} \mathrm{m}^{-3}\right\}$ occurring at the top of the pile. Generally a constitutive equation defines an aspect of the behavior of a material, in this case the response of the dry bulk density $\rho_{s}$ to the stress $\sigma$. Later we present experiments showing the validity of Equation (27) for a mixture of straw and chicken manure. Earlier, Bernstein (1912) used such an expression for the vertical stress in an analysis of the baling process of rye straw.

3 . The compression occurs at constant dry matter content $d_{s}$, so it is convenient to rewrite (27) as

$$
\sigma=E d_{s}\left(\rho-\rho_{u}\right)
$$

where $\rho_{u}$ is the unloaded total density. Later the assumption of a homogeneous gravimetric dry matter content will be verified with some experimentally determined distributions.

Introducing (28) in (26) gives:

$$
\frac{\partial}{\partial z} \rho+\frac{g}{E d_{s}} \rho=0 \text {. }
$$

Integration of (29) subject to $\rho=\rho_{u}$ at $z=Z$ gives:

$$
\rho=\rho_{u} \exp \left[g(Z-z) /\left(E d_{s}\right)\right]
$$

Equation (30) is an expression for the distribution of the bulk density as a function 
of the height z. Substitution of (30) into (13) results in the relation between air filled volume fraction $\theta_{g}$ and height $z$ :

$$
\theta_{g}=1-\left(1+d_{s} / \gamma_{s}-d_{s} / \gamma_{l}\right) \rho_{u} \exp \left[g(Z-z) /\left(E d_{s}\right)\right]
$$

From (30) and (31) some important parameters for composting practice can be deduced. Haug (1993) found that a minimum value of the air filled volume fraction of $30 \%$ is necessary to maintain an optimum composting process. By solving $Z$ from (31) it is possible to calculate a critical value of the pile height $Z_{a}$, depending on a minimum value of the air filled volume fraction $\theta_{g \text { min }}$ at $z=0$ :

$$
Z_{c r}=\frac{E d_{s}}{g} \ln \left\{\frac{\gamma_{s} \gamma_{l}\left(1-\theta_{g \min }\right)}{\left[d_{s} \gamma_{l}+\left(1-d_{s}\right) \gamma_{s}\right] \rho_{u}}\right\} \text {. }
$$

For the design of a composting plant it is desirable to calculate the amount of waste which can be composted per unit area and per unit of time. The weight of composting material per unit area is called the floor load $w$. This floor load is calculated by integration of $\rho$ in (30) from $z=0$ to $z=Z$ :

$$
w=\rho \int_{z=0}^{z=Z} \exp \left[g(Z-z) /\left(E d_{s}\right)\right] d z=\left(E d_{s} \rho_{u} / g\right)\left\{\exp \left[(g Z) /\left(E d_{s}\right)\right]-1\right\} \text {. }
$$

The critical floor load $w_{c r}$, at which the air filled volume fraction at $z=0$ is equal to the minimum value $\theta_{g \text { min }}$, is obtained by replacing $Z$ by $Z_{c r}$ in (33) followed by substitution of (32):

$$
w_{c r}=\frac{E d_{s} \rho_{u}}{g}\left\{\frac{\gamma_{s} \gamma_{l}\left(1-\theta_{g \min }\right)}{\left[d_{s} \gamma_{l}+\left(1-d_{s}\right) \gamma_{s}\right] \rho_{u}}-1\right\} .
$$

This equation can be used to approximate the capacity of the composting plant which is optimal with respect to the minimal value of the air filled volume fraction necessary to meet aeration requirements.

\section{Materials and methods}

In this section we present three identical experiments. Experiments 1 and 2 are used to determine $E$. Experiment 3 is used to examine the validity of equation (28). We realize that it is a rather arbitrary choice to have three identical experiments and then use two of those to identify $E$ and the third one to verify the validity of equation (28).

Composting experiments were carried out with a mixture of chicken manure and wheat straw. The mixture was prepared by chopping $300 \mathrm{~kg}$ of wheat straw to median 
stalk length of about $7.5 \mathrm{~cm}$, wetting the straw during one week by spraying tap water on it and next adding $300 \mathrm{~kg}$ of chicken manure. The mixture was homogenized by passing it several times through a dung spreader. Finally, the mixture consisted of a straw matrix with embedded clods of chicken manure. These clods had a diameter of about 2 to $5 \mathrm{~cm}$. The straw matrix consisted of stalks enveloped by a slurry of manure. For experiments 1, 2 and 3 the initial values of dry matter content $d_{s}$ were equal to $0.20,0.21$ and 0.22 , respectively.

A rectangular container with dimensions $1.47 \times 1.47 \times 1.22=2.64 \mathrm{~m}^{3}$ was made of plywood and provided with a grid floor. This container was filled with six layers of composting material with an initial mass of about $130 \mathrm{~kg}$ each, separated from each other by means of a rigid iron grid mounted in a wooden frame. These grids were used as markers to measure the deformation of individual layers. The grids consisted of a wire netting with a mesh size of $9 \mathrm{~mm}$, which was assumed to be large enough to ensure undisturbed transfer of heat, gases and liquids between the layers. Each grid weighed $15 \mathrm{~kg}$. A thin steel wire was fixed at each corner of the grids. These wires were guided over the brim of the container and were stretched by a small weight.

At filling the distances $h_{1}$ and $h_{2}$ were measured (see figure 2), in which $h_{1}$ is the distance between the grid on top of the most recently stacked layer and the brim of the container and $h_{2}$ the distance between the brim of the container and the end of each wire. When the filling process was completed, the distances $h_{2}$ of each layer were measured. To follow the deformation of the layers during the process, the distances $h_{2}$ were measured at regular time intervals. The values $h_{1}$ and $h_{2}$ were used to calculate the distance between two contiguous grids. The volume of a layer was calculated by multiplying the area of a grid by the distance between the two contiguous grids. At filling the mass of each layer was determined and samples were taken of the raw mixture.

The three experimental runs each lasted four weeks. Usually a compost pile is turned at regular time intervals. In this study the time interval was one week. At the end of each period of seven days the compost pile was taken down and rebuilt layer by layer. Each layer of composting material was well mixed, weighed, sampled and kept separate from the other layers. When the pile was rebuilt, the individual layers

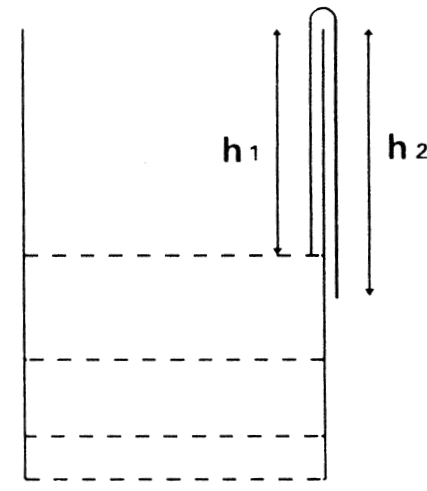

Figure 2. Heights measured when the pile was (re)built. Height $h_{1}$ is the distance between the most recently stacked grid and the brim of the container; $h_{2}$ is the distance between the brim and the end of the wire attached to the corner of the grid. 
were stacked in the same order as the week before. Samples were taken to determine the dry matter content $d_{s}$. Each sample was weighed, dried at $105^{\circ} \mathrm{C}$ and weighed again. The unloaded total bulk density $\rho_{u}$ of a layer was defined as the total bulk density of that layer at the moment it was just stacked on the pile and one single grid was placed on top of it. The stress exerted on a layer was calculated as the sum of weights of the layers, including the grids placed above the considered layer, plus half of its own weight.

The air-filled volume fraction $\theta_{g}$ was measured in the laboratory by means of an air pycnometer as described by Day (1964). It uses the principle of Boyle's law. The air-filled volume fraction of a sample is calculated from the resulting pressure when a gas at a measured volume and pressure expands into a larger volume, which includes the sample. The error in the air-filled volume fractions measured by this pycnometer was $0.04 \mathrm{~m}^{3} \mathrm{~m}^{-3}$.

\section{Results}

\section{Verification of assumption of a homogeneous gravimetric dry matter content}

The assumption of a homogeneous gravimetric dry matter content can be compared with some experimentally determined distributions. The results are given in Figures $3 \mathrm{a}$ to $3 \mathrm{c}$. Figures $3 \mathrm{a}$ and $3 \mathrm{~b}$ show the dry matter distributions at the start and at day 7 of experiments 1 and 2, respectively. The respective initial dry matter contents of the experiments 1 and 2 were 0.20 and 0.21 . Figure 3 a shows that the dry matter content changed from 0.20 to an average value of 0.25 on day 7 . The largest deviation from the average value at day 7 occurred in the top layer. Here, the dry matter content was 0.19 . Figure $3 \mathrm{~b}$ shows that the distribution of the dry matter did not change during the seven days period, except for the bottom layer. Apart from the small difference between the initial water contents, we do not have an explanation for the difference between experiments 1 and 2 .

Figure 3c gives the dry matter distributions at day 0 and day 14 of experiment 3. The composting material used in this experiment had an initial dry matter content of 0.22 . The dry matter distribution at day 14 is approximately parallel to the distribution at day 0 . The assumption of a homogeneous dry matter distribution only pertains to the moment the pile has just been set up. After that moment redistribution of water can occur. Therefore it can be expected that the distributions at the end of day 0 will be more homogeneous than at days 7 and 14 shown in the figures $3 \mathrm{a}$ to $3 \mathrm{c}$. From these figures it is concluded that, as a first approximation, the assumption of homogeneity is acceptable for compost piles at day 0 with a maximum height of 1.2 $\mathrm{m}$ and a dry matter content larger than 0.20 .

To check the validity of the assumption in more detail, it is necessary to analyze the behavior of the liquid fraction. The assumption is valid as long as the liquid fraction is stationary relative to the matrix of dry organic matter. Information about the pressure head and the hydraulic conductivity of composting material is needed to describe the transport of water in a compost pile. As hardly any information about 
Pile height $[\mathrm{m}]$

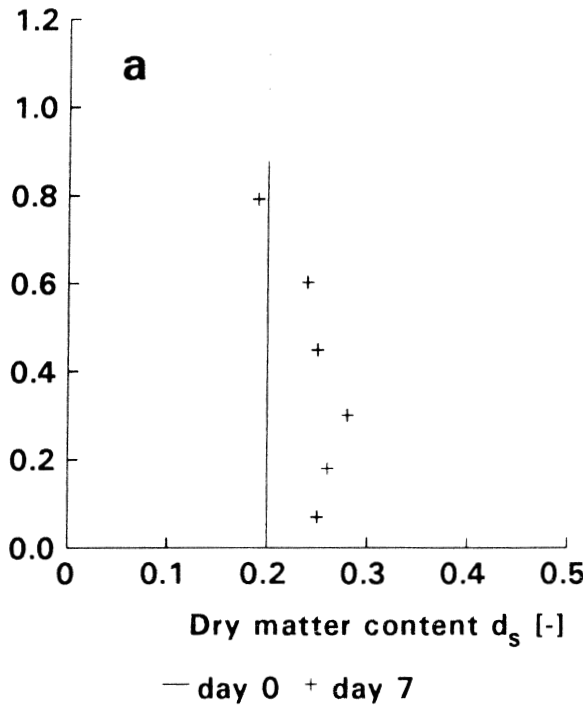

Pile height $[\mathrm{m}]$

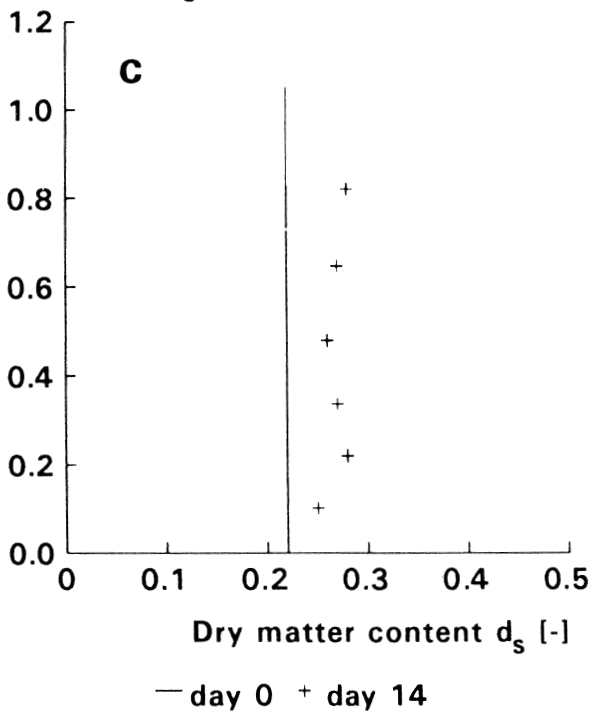

Pile height $[\mathrm{m}]$

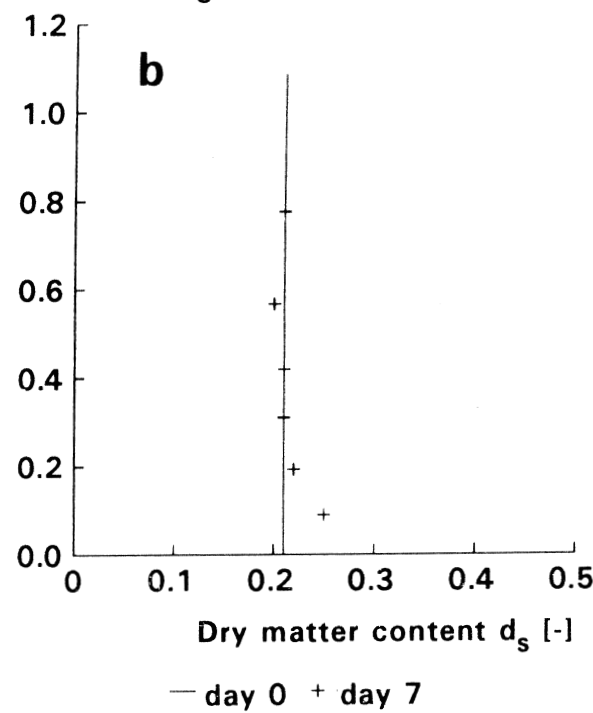

Figure 3. Distribution of the dry matter content $d_{s}$ of experiments (a) 1, (b) 2 and (c) 3, respectively. The respective values of the initial dry matter content were $0.20,0.21$ and 0.22 .

these transport parameters of composting material is found in the literature, it is impossible to determine if and to what extent transport of water will occur. However, it is certain that the discharge of water starts if the air filled volume fraction becomes zero as a result of compression. Then, the assumption of a homogeneous gravimetric 
dry matter content is no longer valid and (30) no longer holds. A second reason that (30) becomes invalid, is the changing value of $E$ if the air-filled volume fraction becomes zero and water seeps out. Further, it has to be emphasized that $Z$ and $d_{s}$ are functions of time because water and dry matter are lost during the composting process.

\section{Implications of the vertical force balance}

To determine the value of $E$, equation (28) is written as:

$$
E=\frac{\sigma}{d_{s}\left(\rho-\rho_{u}\right)} .
$$

We obtained values of stress, dry matter content and bulk density from experiments 1 and 2 at the start of weeks 1, 2, 3 and 4. Organic matter decomposes during the composting process, which may influence the mechanical strength of the material. We expected the value of $E$ to be higher at the start of week 1 than at the start of week 4. However, the difference between both values is not significant at a reliability level of $95 \%$. Hence, we decided to consider each instant the pile was (re)built as the start of a new experiment independent from the other. Figure 4a shows the relationship between $\left(\rho_{s}-\rho_{s u}\right)$ and $\sigma_{i}$. The intercept of the straight line is not statistically significant at $95 \%$ reliability. The value $E$ obtained from the slope of the line is $73 \mathrm{~J} \mathrm{~kg}^{-1}$ with a standard error of $5 \mathrm{~J} \mathrm{~kg}^{-1}$.

We checked the validity of (28) by comparing values of total bulk density calculated from:
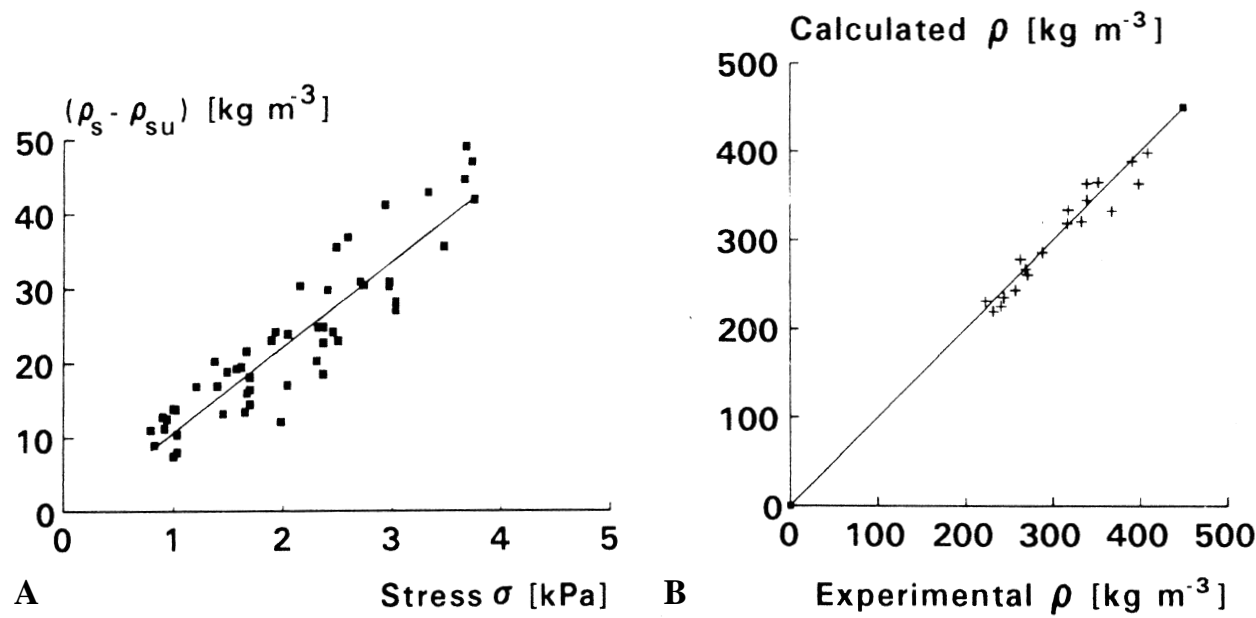

Figure 4. a) Deformation of dry material as a function of stress $\sigma$. The deformation is expressed as the difference between the dry bulk density $\rho_{s}$ and the unloaded dry bulk density $\rho_{s u}$; b) Relation between calculated and observed values of the total bulk density $\rho$. Observed data are obtained from experiment 3. Calculated data are computed by (36) with $E=73 \mathrm{~J} \mathrm{~kg}^{-1}$, based on experiment 1 and 2 . 


$$
\rho=\rho_{u}+\frac{\sigma}{E d_{s}},
$$

with $E$ equal to $73 \mathrm{~J} \mathrm{~kg}^{-1}$, and experimental values of total bulk density obtained from experiment 3 . Figure $4 \mathrm{~b}$ shows the relationship between calculated and experimental bulk density values. Regression analysis of experimental and calculated values shows that there was no difference between the regression line through the points and the bisector at a reliability level of $95 \%$. The error of values calculated by (36) is approximated from the confidence band of the regression line in Figure $4 \mathrm{~b}$ and is equal to an average value of $12 \%$ at the same reliability level.

\section{The true densities of the solid phase and the organic matter}

We computed the true density $\gamma_{s}$ of the dry matter of composting material by means of Equation (15) with measured values of total bulk density $\rho$, dry matter content $d_{s}$ and air-filled volume fraction $\theta_{g}$. Usually, the value of an experimentally determined quantity is given as the average of a number of observations and its accuracy is given by the standard error on the mean. For the true densities calculated on the basis of (15), this leads to unrealistic values as a result of the small amounts of dry matter contained in the samples. Therefore, the sample with the largest $\theta_{s}$ was chosen. This sample consisted of 5 weeks old composting material. The resulting value of $\gamma_{s}$ is 1.9 $\times 10^{3} \pm 400 \mathrm{~kg} \mathrm{~m}^{-3}$.

To determine the true density $\gamma_{\circ}$ of organic matter, we calculated the ash concentration $c_{a}$ on the basis of 12 replicates. The resulting value is 0.44 . The ash fraction consists of minerals. The ash fraction of wheat straw contains $91 \%$ silica (Staniforth, 1979) and the ash fraction of chicken manure contains a large amount of sand and lime from the grit admixed in chicken feed as a calcium source (Hafez et al., 1974). The true densities of sand and lime are equal to $2.65 \times 10^{3}$ and $2.7 \times 10^{3} \mathrm{~kg} \mathrm{~m}^{-3}$, respectively (De Vries, 1963). Both values are of the same order of magnitude. No more quantitative information about the chemical composition of ash is available yet. For calculation purposes we therefore assumed that ash only consists of sand and adopted the value $2.65 \times 10^{3} \mathrm{~kg} \mathrm{~m}^{-3}$ as the true density for it. The true density of organic matter can now be computed by means of (24) and is found to be $1.6 \times 10^{3} \pm$ $400 \mathrm{~kg} \mathrm{~m}^{-3}$. The true density of cellulose, one of the most important constituents of plant materials, is equal to $1.66 \times 10^{3} \mathrm{~kg} \mathrm{~m}^{-3}$ (Weast, 1985). This value is close to the magnitude of $\gamma_{o}$ found in this study. Busse (1964) gives a value of $1.5 \times 10^{3} \mathrm{~kg} \mathrm{~m}^{-3}$ for compressed straw and Dexter (1964) found the same value for the true density of the dry matter of alfalfa calculated from water pycnometer measurements. These values also have the same order of magnitude. However, De Vries (1963) cites a value of $1.26 \times 10^{3} \mathrm{~kg} \mathrm{~m}^{-3}$ for humus in soils. Humus can be considered as the final product of the degradation of plant materials and it is chemically different from cellulose. After only 4 weeks of thermophilic composting the state of total humification is not approached by far. It is therefore not surprising that the value of $\gamma_{o}$ found in this study lies between that of cellulose and humus. 
The analytical data obtained from literature cited above are given without estimates of errors because no information about experimental errors was included in these literature data.

\section{Change of relative ash content in the course of time}

The ash content in dry matter of composting material will increase during the process. To describe the time course of the ash content, it appears to be most appropriate to divide the actual ash concentration $c_{a}$ by its initial value. The course of this relative ash content $\chi_{a}$ is given in Figure 5. The values shown in this figure are average values based on 10 replicate samples. Nonlinear regression analysis of the experimental data gives:

$$
\chi_{a}=1.0+0.9[1-\exp (-0.02 t)]
$$

in which $t$ is the process time [day]. This regression equation accounts for $92.6 \%$ of the variance. To calculate the time course of the true density of dry matter, Equation (24) is solved for $\gamma_{s}$ :

$$
\gamma_{s}=\left(\frac{1-c_{a}}{\gamma_{a}}+\frac{c_{a}}{\gamma_{a}}\right)^{-1}
$$

Based on Equations (37) and (38), we computed the time course of $\gamma_{s}$ during the process, using a starting value of 0.29 for the ash content $c_{a}$. During the thermophilic stage of the process, the value of $\gamma_{s}$ increased from $1.8 \times 10^{3}$ to $1.9 \times 10^{3} \mathrm{~kg} \mathrm{~m}^{-3}$. This increase may be regarded as insignificant compared to the value of $400 \mathrm{~kg} \mathrm{~m}^{-3}$ for the standard deviation of $\gamma_{s}$. Therefore, we used an average value of $1.85 \times 10^{3} \mathrm{~kg}$ $\mathrm{m}^{-3}$ for $\gamma_{s}$ in computations and neglected the dynamic changes of this value during the composting process.

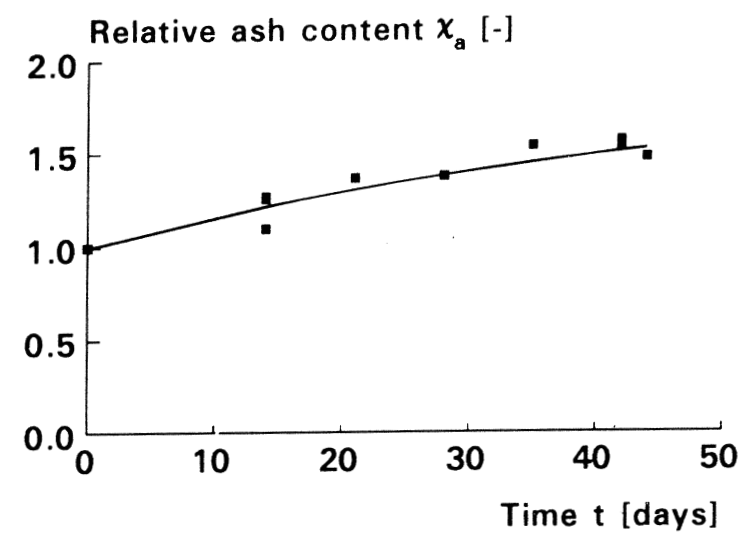

Figure 5. Relative ash content $\chi_{a}$ a function of the process time. 


\section{Time course of settlement}

The dynamic changes of $\rho$ and $\theta_{s}$ are shown in Figures $6 \mathrm{a}$ and $6 \mathrm{~b}$ and in Table 1. Figure $6 \mathrm{a}$ gives the position of the top of separate layers during the first week of experiment 3. This figure shows that the largest volume reduction occurred in the top layer during the first two days. Figure $6 \mathrm{~b}$ gives analogous information for the last week (week 4) of experiment 3, when the volume reduction was very small.

Table 1 presents data about the relative volume changes due to subsidence and material loss only. We calculated material loss from measured values of dry matter and

Table 1. Relative volume changes due to subsidence and material loss during the first and last week of experiment $3 . \mathrm{V}_{\mathrm{i}}$ is the initial volume of a layer at the start of each week $\left[\mathrm{m}^{3}\right], \Delta \mathrm{V}$ is the total decrease of volume of a compost layer $\left[\mathrm{m}^{3}\right], \Delta \mathrm{V}^{\prime}$ is the volume decrease resulting from loss of dry matter and water only $\left[\mathrm{m}^{3}\right]$ and $l$ is the number of the compost layer (layer 1 is the bottom layer and layer 6 is the top layer).

\begin{tabular}{lllll}
\hline layer & week 1 & \multicolumn{3}{c}{ week 4} \\
\cline { 2 - 5 } & $\left.\left(\Delta \mathrm{V}^{\prime}-\Delta \mathrm{V}^{\prime}\right) / \mathrm{V}_{\mathrm{i}}\right)$ & $\Delta \mathrm{V}^{\prime} / \mathrm{V}_{\mathrm{I}}$ & $\left(\Delta \mathrm{V}-\Delta \mathrm{V}^{\prime}\right) / \mathrm{V}_{\mathrm{I}}$ & $\Delta \mathrm{V}^{\prime} / \mathrm{V}_{\mathrm{i}}$ \\
6 & 0.50 & 0.02 & 0.09 & 0.03 \\
5 & 0.27 & 0.03 & 0.15 & 0.02 \\
4 & 0.24 & 0.04 & 0.16 & 0.02 \\
3 & 0.22 & 0.05 & 0.13 & 0.02 \\
2 & 0.17 & 0.04 & 0.11 & 0.03 \\
1 & 0.19 & 0.05 & 0.14 & 0.04 \\
\hline
\end{tabular}
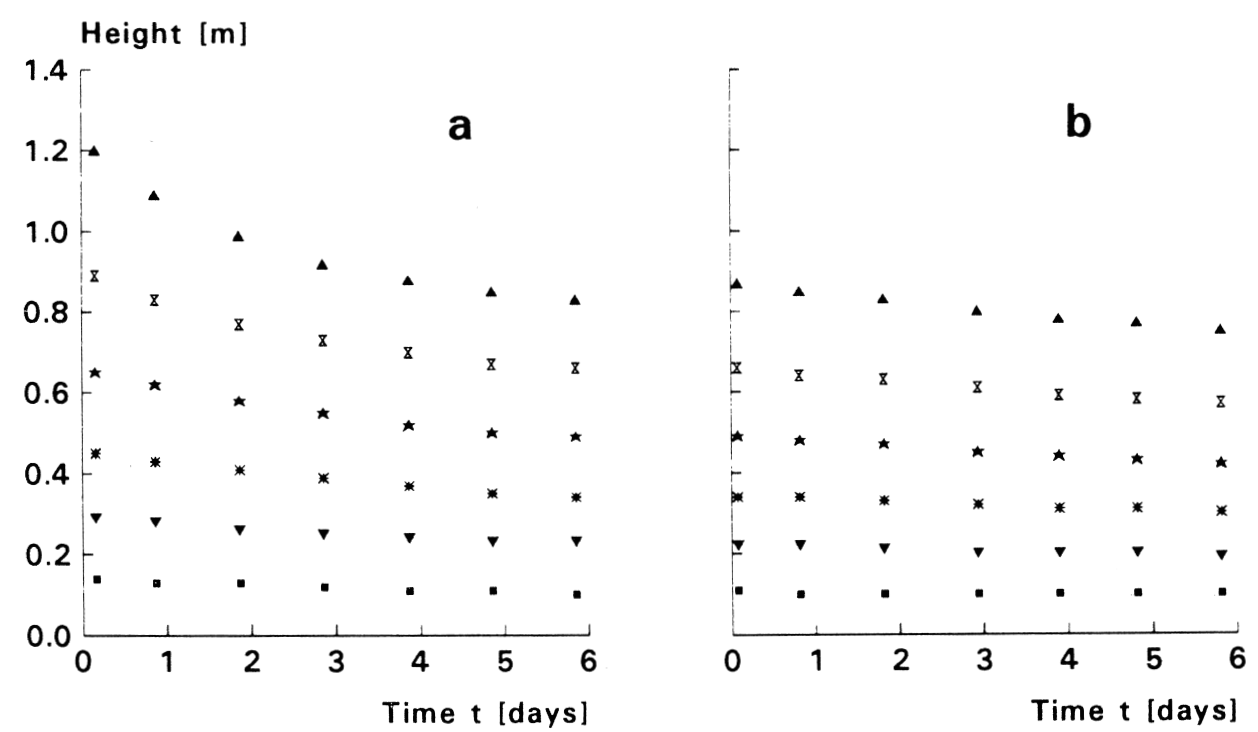

Figure 6. The time course of the top of separate layers during (a) the first week and (b) the last week of experiment 3 . 
water loss divided by their respective true densities. We computed subsidence as $\left(\Delta \mathrm{V}-\Delta \mathrm{V}^{\prime}\right) / \mathrm{V}$. During both weeks the volume reduction due to material loss was small, about $4 \%$ in week 1 and $3 \%$ in week 4 . The volume reduction due to subsidence varied, on average, from $27 \%$ during the first to $13 \%$ during the last week. During the first week subsidence tended to decrease going from the top to the bottom layer. This tendency was absent in week 4.

\section{Discussion and conclusions}

Predicted values of total bulk density $\rho$ as a function of height calculated by Equation (30) are depicted by the line in Figure 7a. These calculated values can only be compared with observed data at the start of the process when the amount of displaced water is regarded as negligible. This follows from the assumption that the gravimetric dry matter content is independent of position. In the same figure observed data from the start of experiment 3 are indicated by asterisks. The observed values and the curve of calculated data are almost parallel, which indicates that the water content $d_{s}$ was independent of height at the start of the process. Of course, the calculated values slightly underestimate the observed data because the weight of the grids is not accounted for in (30).

It is interesting to compare this bulk density distribution with experimental distributions reported by other authors. Ohm (1972) described three experiments with hay. Two of them (A and C) were performed with chopped hay, with dry matter contents of 69 and $68 \%$ respectively, while the third experiment (B) was carried out with unchopped hay with a dry matter content of $74 \%$. In Figure $7 \mathrm{~b}$ the curves represent values calculated by (30). In these calculations we assumed the value of the bulk modulus $E$ to be $73 \mathrm{~J} \mathrm{~kg}^{-1}$. The experimental data, including values of unloaded bulk density, are obtained from Ohm (1972, p. 82, graph 3-5B). Figure 7b clearly shows the validity of equation (30) with respect to chopped hay. It is remarkable that $\rho$, ob-
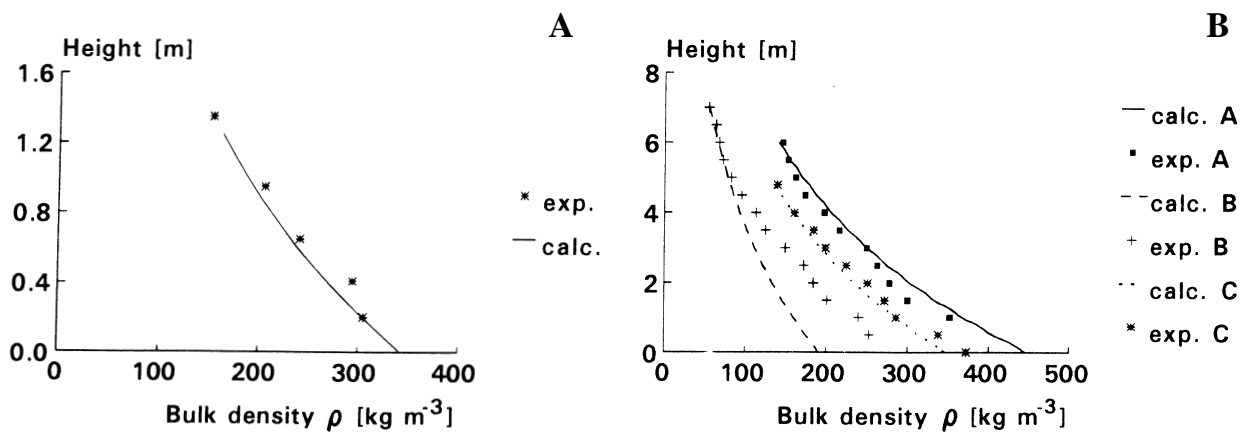

Figure 7. a) Relation between total bulk density $\rho$ and height. The line indicates values calculated by (30) and the points indicate data observed at the start of experiment 3; b)The relationship between calculated and observed total bulk densities and height. Observed data were obtained from Ohm (1972). Experiments A and C were carried out with chopped hay, whereas in experiment B unchopped hay was used. Calculated values are computed by (30). 


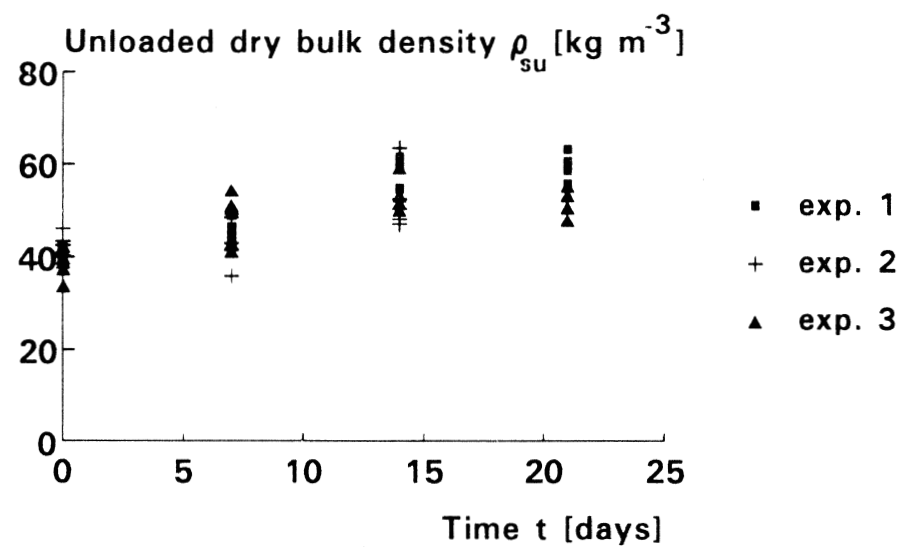

Figure 8. Unloaded dry bulk densities measured during experiments 1,2 and 3 as a function of time.

tained from experimental data of composting material with a dry matter content of approximately $25 \%$ also gives good results for chopped hay with a dry matter content of about $70 \%$. Equation (30) seems not to be appropriate to predict the behavior of unchopped hay.

We attempted to describe the course of unloaded total bulk density during the process. However, no correlation exists between unloaded bulk density and time. We also investigated the time course of the unloaded dry bulk density $\rho_{s u}$ during the process. Figure 8 gives the experimental results. The figure shows that the unloaded dry bulk density increased from an average value of 38 at the start to $53 \mathrm{~kg} \mathrm{~m}^{-3}$ at the end of the process.

From the results it can be concluded that:

1. The relationship between bulk density and height and the relationship between airfilled volume fraction and height, as presented in section 3.1, are valid for composting material consisting of chopped wheat straw and chicken manure.

2. The check of this validity is limited to total bulk density values ranging from 150 to $950 \mathrm{~kg} \mathrm{~m}^{-3}$, with values of dry matter content varying between 18 and $28 \%$ (w.b.). Moreover, the gravimetric dry matter content must be constant throughout the total cross section of the pile.

3 . The error in the calculated bulk densities and air-filled volume fractions was found to be $12 \%$ at a reliability level of $95 \%$.

4. It seems likely that the presented equations will give reasonable results for other values of dry matter content and other kinds of chopped fibrous materials, as long as the gravimetric dry matter content remains independent of height.

\section{Acknowledgements}

The experiments described in this paper were carried out at the former Institute for Soil Fertility Research (IB-DLO) at Haren, The Netherlands. The material costs of this research were borne by The National Research Program on Reuse of Waste Ma- 
terials, commissioned by the Dutch Organisation for Energy and Environment (NOVEM), grant no. 24.21-500.10.

\section{References}

Bernstein, R., 1912. Eine Characteristik der Strohpresse. Mitteilungen des Verbandes landwirdtschaftlicher Maschinen-Prüfungsanstalten 6: 161- 165.

Busse, W., 1964. Die Theorie auf dem Gebiet des Verdichtens landwirtschaftlicher Halmgüter. Institut für Landmachinen. Landtechnische Forschung 14: 6- 15.

Day, C.L., 1964. A device for measuring voids in porous materials. Agricultural Engineering January issue: $36-37$.

De Vries, D.A., 1963. Thermal properties of soils. In: W.R. Van Wijk (Ed.), Physics of plant environment. North Holland Publishing Company, Amsterdam, 382 pp.

Dexter, S.T., 1964. Physical constants in Alfalfa (Medicago Sativa L.) silage and silage materials. Crop Science 4: 599-602.

Hafez, A.A.R., J. Azevedo, J. Rubin, \& P.R. Stout, 1974. Physical properties of farm animal manures. Bulletin 867 California Agricultural Experimental Station.

Haug, R.T., 1993. The practical handbook of compost engineering. Lewis, Boca Raton, 717 pp.

Lopez-Real, J., 1990. Agro-industrial waste composting and its agricultural significance. Proceedings of the Fertilizer Society: 3- 26.

Lyons, L., 1991. A practical guide to data analysis for physical science students. Cambridge University Press, 95 pp.

Ohm, A., 1972. Selfheating and drying processes in hay.(In Dutch). Ph.D. Thesis Technical University Delft; Offsetdrukkerij "Luna”, Delft, 183 pp.

Raats, P.A.C., 1984. Applications of the theory of mixtures in soil science. In: C. Truesdell, Rational thermodynamics. Appendix 5D. Springer Verlag, New York. 326-343.

Raats, P.A.C., 1998a. Kinematics of subsidence of soils with a non-conservative solid phase. In: Proceedings on CD-ROM of a symposium on "New concepts and theories in soil physics" at the 16th World Congress of Soil Science, held 20-26 August 1998 at Montpellier, France.

Raats, P.A.C., 1998b. Spatial and material description of some processes in rigid and non-rigid saturated and unsaturated soils. In: J.-F Thimus et al. (editors) Poromechanics. A tribute to Maurice A. Biot. Balkema, Rotterdam, The Netherlands, pp.135-140.

Randle, P.E. \& P.B. Flegg, 1985. The effect of duration of composting on compost density and yield of mushrooms. Scientia Horticulturae 27:21-31.

Staniforth, A.R., 1979. Cereal straw. Oxford, Clarendon. 175 pp.

Van Ginkel, J.T., 1996. Physical and biochemical processes in composting material. PhD Thesis. Wageningen Agricultural University, $179 \mathrm{pp}$.

Weast, R.C., 1985. CRC Handbook of chemistry and physics. CRC press, Boca Raton, 2000 pp. 